\title{
A PRESENÇA MISSIONÁRIA DE PROTESTANTES NO BRASIL E OS 500 ANOS DA REFORMA: UMA INTRODUÇÃO
}

\author{
THE MISSIONARY PRESENCE OF PROTESTANTS IN BRAZIL \\ AND THE 500 YEARS OF REFORM: AN INTRODUCTION \\ LA PRESENCIA MISIONERA DE PROTESTANTES EN BRASIL \\ $Y$ LOS 500 AÑNS DE LA REFORMA: UNA INTRODUCCIÓN
}

\author{
Cesar Romero Amaral Vieira ${ }^{1}$ \\ Thiago Borges de Aguiar ${ }^{2}$
}

\begin{abstract}
Resumo Esta é a introdução do Dossiê "Pensando a Educação 500 anos após Wittenberg". O dossiê possui por objetivo problematizar e refletir a respeito da relevância, das repercussões e das influências que o pensamento reformado legou para o campo da educação ocidental, e, em particular, para a brasileira. Neste artigo, apresentamos uma introdução aos modos de inserção de grupos protestantes na dinâmica da sociedade brasileira em formação, em especial no período que vai da vinda dos primeiros colonizadores franceses (meados do século XVI) até a chegada dos primeiros missionários protestantes (segunda metade do século XIX). Nossas principais considerações apontam que o protestantismo transplantado para o Brasil, definido como protestantismo histórico de missão, foi fortemente influenciado pela visão de mundo da igreja metodista norte-americana que encontrou no confronto de adaptação nos Estados Unidos as condições ideais para o seu desenvolvimento. Ao final, discutimos possíveis relações entre os artigos do dossiê, compreendendo como eles permitem dar visibilidade a pesquisas já realizadas sobre educação e Reforma e apontar novas possibilidades de investigação.
\end{abstract}

Palavras-chave: Reforma Protestante, Escola, Missão, Brasil

Universidade Metodista de Piracicaba.

2 Universidade Metodista de Piracicaba. 
Abstract This is the introduction to the Dossier "Thinking about Education 500 years after Wittenberg". The purpose of the dossier is to problematize and reflect on the relevance, repercussions and influences that the reformed thought bequeathed to the field of Western education, and in particular to the Brazilian one. In this article, we present an introduction to the ways of insertion of Protestant groups into the dynamics of Brazilian society in formation, especially in the period from the early French settlers (mid 16th century) to the arrival of the first Protestant missionaries (second half of the 19th century). Our main considerations point out that Protestantism transplanted to Brazil, defined as historical mission Protestantism, was strongly influenced by the world view of the North American Methodist church that found in the confrontation of adaptation in the United States the ideal conditions for its development. In the end, we discussed possible links between the articles in the dossier, understanding how they make it possible to give visibility to research already done on education and reform and to point out new possibilities for research.

Keywords: Reforma Protestante, Escola, Missão, Brasil

Resumen Esta es la introducción del Dossier "Pensando la Educación 500 años después de Wittenberg". El dossier tiene por objetivo problematizar y reflexionar acerca de la relevancia, de las repercusiones y de las influencias que el pensamiento reformado legó para el campo de la educación occidental, y, en particular, para la brasileña. En este artículo, presentamos una introducción a los modos de inserción de grupos protestantes en la dinámica de la sociedad brasileña en formación, en especial en el período que viene de la venida de los primeros colonizadores franceses (mediados del siglo XVI) hasta la llegada de los primeros misioneros protestantes (segunda mitad del siglo XIX). Nuestras principales consideraciones apuntan que el protestantismo trasplantado a Brasil, definido como protestantismo histórico de misión, fue fuertemente influenciado por la visión de mundo de la iglesia metodista norteamericana que encontró en el enfrentamiento de adaptación en Estados Unidos las condiciones ideales para su desarrollo. Al final, discutimos posibles relaciones entre los artículos del dossier, comprendiendo cómo ellos permiten dar visibilidad a investigaciones ya realizadas sobre educación y Reforma y apuntar nuevas posibilidades de investigación.

Palabras clave: Reforma Protestante, Escuela, Misión, Brasil

\section{INTRODUÇÃo}

Embora concordamos com a observação de Jean-Pierre Bastian (1992, p. 467) de que "a historiografia latino-americana pouco se interessou pelo fenômeno religioso protestante", é possível perceber a contribuição de alguns "pesquisadores audaciosos" que se tornaram referências obrigatórias para a análise histórica e sociológica da presença do protestantismo no Brasil. Podemos citar algumas obras como a de Roger Bastide - Religion and the Church in Brazil (1951); Emile G. Leonard - O protestantismo brasileiro: estudo de eclesiologia e história social (1981); David Gueiros Vieira - O protestantismo, a maçonaria e a Questão Religiosa no Brasil (1980); Ducan A. Reily - História documental do 
protestantismo no Brasil (1984); Antônio Gouvêa Mendonça - O celeste porvir: a inserção do protestantismo no Brasil (1984); Martin N. Dreher - Protestantismo de inmigración en Brasil (1989). O que de fato, não nos impede de continuar concordando com Bastian de que ainda predomina na historiografia, tanto latino-americana como na nacional, narrativas clivadas por um discurso apologético dos agentes das próprias denominações e/ou de visões particularizadas que se afastam de uma interpretação científica do fenômeno em si.

No campo da História da Educação a carência de investigações que ultrapassem "o círculo vicioso da análise subjetiva e apologética", como alerta Bastian (1992, p. 467), ainda é mais evidente, apesar de reconhecermos que hoje existe um discreto incremento de pesquisas neste domínio, materializadas na produção de dissertações, teses e publicações científicas em periódicos acadêmicos de relevância por todo o país. Temos reiteradamente afirmado que a variedade de fontes disponíveis sobre esta presença aponta-nos para a necessidade do estabelecimento de um referencial teórico multidisciplinar capaz de apreender este fenômeno a partir da dinâmica de sua construção histórica em sua interação com a sociedade brasileira nas esferas social, política, religiosa e cultural. Ao nosso ver, o campo da História da Educação brasileira ainda está aberto a novas investigações que avancem na análise dos processos pedagógicos, práticas educativas e culturas escolares postas em circulação pelos colégios implantados por estas sociedades que tiveram grande relevância, principalmente no período de transição do Impérios para a República (Cf. VIEIRA, 2016, p. 134).

Este artigo e o dossiê que ele encabeça propõem-se a colaborar na produção e divulgação dessas investigações que permitem problematizar e refletir a respeito da relevância, das repercussões e das influências que o pensamento reformado legou para o campo da educação ocidental, e, em particular, para a brasileira (como escrevemos na ementa do Dossiê "Pensando a Educação 500 anos após Wittenberg"). Neste texto em particular, iremos percorrer o itinerário da presença protestante no Brasil de um modo um tanto quanto introdutório, pois não está em nosso horizonte abarcar o conjunto das manifestações protestantes em solo brasileiro, muito menos, olhar separadamente para um determinado segmento. Nosso objetivo maior é descrever a inserção de sociedades protestantes na dinâmica da sociedade brasileira em formação nestes aproximados 500 anos de história. Muito embora o protestantismo originário da Reforma quinhentista não seja necessariamente fruto de uma mesma mentalidade (já que Lutero e Calvino, para falarmos apenas dos dois reformadores, afastaram-se quanto a alguns princípios fundamentais para uma unidade teológica, principalmente a respeito do homem e de Deus) podemos dizer que toda forma particular do protestantismo tem como princípio norteador a Reforma do século XVI, mesmo levando em conta os confrontos históricos que o protestantismo realizou até seu estabelecimento na américa-latina. Segundo Bastian,

As reformas protestantes levaram consigo uma pluralidade de organizações religiosas, de modelos eclesiológicos que, apenas com muitas distinções, permitem falar de protestantismo desde um ponto de vista genérico, mesmo quando, no início, exista um mínimo denominador comum baseado nesses três grandes princípios: sola fides, sola gratia, sola scriptura. (BASTIAN, 1994, p. 7) 
Diferentemente do catolicismo que sempre se beneficiou da tradição, o protestantismo, regra geral, por sua natureza plural, nunca foi uma religião de adaptação passiva. As organizações sociais as quais ajudou a formar ao longo de sua história guardam peculiaridades distintas da sociedade onde se desenvolveram, estabelecendo um certo conflito em relação a cultura do lugar. Isto se deve em grande parte à necessidade de preservação do instituto religioso em relação ao novo espaço habitado. Podemos dizer que, quanto maior a diversidade encontrada em relação ao seu contexto originário, maior foi a oposição à cultura estabelecida que o protestantismo teve de fazer para se estabelecer, e mais difícil foi o seu processo socializador (VIEIRA, 2000, p. 48-49).

\section{SOCIEDADES PROTESTANTES NO ESPAÇO GEOPOLÍTICO COLONIAL}

A primeira movimentação da fé reformada no Brasil foi logo registrada na segunda metade do século XVI, mais precisamente em 11 outubro de 1555, e contou com o envolvimento da recente Igreja Reformada de Genebra, em resposta a uma solicitação do controverso Almirante Nicolas Durand de Villegagnon, pretenso fundador de uma colônia francesa no Rio de Janeiro que chegou na baía de Guanabara e logo estabeleceu-se em uma ilha deserta próxima ${ }^{3}$ para construir uma fortificação apropriada batizada de Forte Colligny, em homenagem ao almirante Gaspard de Colligny, chefe do partido dos huguenotes francês. Um ano após a chegada endereçou uma carta ao reformador João Calvino comunicando-lhe a pretensão de estabelecer no Brasil um lugar onde pudesse livremente cultivar os ideais do Evangelho reformado e "preparar um refúgio para todos os que desejassem fugir das perseguições" religiosas em curso na França e demais países europeus (LÉRY, 1961, p. 40).

Em atendimento a esta solicitação, no dia 10 de março de 1557, chegou uma comitiva de genebrinos e franceses dispostos a desenvolver a colonização nesta parte da América ${ }^{4}$. Além dos ministros Pedro Richier e Guilherme Chartier um dos integrantes dessa comitiva era o jovem Jean de Léry, estudante de teologia que mais tarde se tornaria ministro do evangelho e publicaria o livro Viajem à terra do Brasil, editado em Paris pela primeira vez em 1578 . Após as apresentações e declaração das causas principais que trouxeram o grupo a terras tão distantes foi realizado, no mesmo dia, numa quarta-feira, no Forte Colligny, o primeiro culto protestante em terras brasileiras dirigido pelo ministro reformado Richier ${ }^{5}$. Entretanto, o sonho de estabelecer a França Antártica em terras tupiniquins não logrou êxito. Controvérsias internas quanto à mudança de postura teológica de Villegagnon a respeito da fé reformada; o tratamento cruel dispensado aos franceses e demais seguidores; e a resistência dos portugueses a essa empreitada puseram termo às suas pretensões, culminando com a expulsão dos invasores e a completa destruição do Forte Colligny, em 11 de maio de 1560, pelo governador português Mem de Sá que pôs fim a sanha francesa em seus domínios.

\footnotetext{
3 Hoje esta ilha encontra-se nas imediações do aeroporto Santos Dumont, na cidade do Rio de Janeiro.

4 Léry cita o nome de 14 desses reformados que saíram de Genebra no dia 16 de setembro de 1556 . A estes se juntaram mais alguns fidalgos franceses adeptos da religião reformada (Ver. LÉRY, 1961, p. 42 e 43).

5 Informações extraídas do apêndice do livro O martyr le balleur de Álvaro Reis, 1917. Ver também, Jean de Léry, Viagem à terra do Brasil (1961).
} 
Assim escreveu Anchieta ao Infante Dom Henrique a respeito dos hereges protestantes franceses que ameaçavam "a integridade ideológica e política de uma unidade sociopolítica complexa erigida no modelo da cristandade” (BASTIAN, 1992, p. 468):

Todos eles (franceses) eram hereges, aos quais mandou João Calvino dois que lhes chamam Ministros, para lhes ensinar o que haviam de ter e crer. Daí a pouco tempo, como é costume dos hereges, começaram a ter diversas opiniões uns dos outros, mas concordavam nisto que servissem a Calvino e a outros letrados. (ANCHIETA, 1988, p. 167)

Os franceses tentaram mais uma vez invadir o Brasil em 1612 e fundar a França Equinocial no Maranhão e Grão-Pará sob o comando do fidalgo protestante Daniel de la Touche de la Ravardière. Tentativa esta que durou apenas três anos antes de serem completamente expulsos do domínio português. Nessa expedição havia um significativo contingente de huguenotes atraídos pelo aparente clima de liberdade religiosa que reinava entre os franceses, sobre a proteção do Édito de Nantes de $1598^{6}$, entretanto, após a morte de Henrique IV, a expedição foi conduzida sob forte controle da intransigente rainha católica Marie de Médici, cujo objetivo era a destruição da obra de seu marido (Cf. PROVENÇAL, 2009, p. 71).

Apesar de uma anterior investida frustrada de penetração na Bahia em 1624-1625, a segunda presença mais efetiva de protestantes no Brasil se deu no período da conquista de Olinda e do Recife pelos holandeses em 1630, reconhecida por Mendonça como "a mais séria e duradoura tentativa de implantar uma civilização protestante no Brasil» (1984, p.18), patrocinada pela Companhia das Índias Ocidentais (West-Indische Compagnie). A presença holandesa, ou como ficou conhecido o Brasil Holandês estendeu-se por toda Pernambuco e grande parte do nordeste brasileiro entre os anos de 1630 a 1654, e durante este período logrou êxito ao conseguir um controle quase que completo tanto da ordem civil quanto política, embora os holandeses tenham se mostrado bastante tolerantes com o catolicismo e com o judaísmo ${ }^{7}$. De acordo com Schalkwijk (1997), há indicação de que foram fundadas 22 igrejas reformadas holandesas no Nordeste, sendo a do Recife a mais importante com uma congregação inglesa e uma francesa onde Mauricio de Nassau era o membro mais ilustre. Contudo, seguindo o mesmo modelo da primeira invasão no Rio de Janeiro, os protestantes holandeses não tiveram a intenção de estender a obra da Igreja Reformada em grande escala sobre o conjunto da sociedade brasileira, estavam mais preocupados em encontrar um lugar onde pudessem prosperar e praticar livremente sua fé.

Um ano após a renúncia do governo de João Mauricio de Nassau-Siegen ${ }^{8}$ a frente desse empreendimento (1637-1644), os holandeses foram expulsos por uma força luso-brasileira

6 Édito de Nantes ou Édito da Pacificação foi assinado por Henrique IV e estabeleceu uma política de tolerância religiosa que pôs fim a perseguição aos protestantes franceses em todo o seu território e possessões que duraria até meados do século XVII.

7 Centenas de judeus de origem portuguesa que viviam em Amsterdã instalaram-se no Recife, atraídos pelo clima de tolerância religiosa patrocinada pelos holandeses. Lá foi construída a primeira sinagoga das Américas no ano de 1636 .

8 Por sua habilidade política e tolerância religiosa, o período nassoviano constituiu-se como uma espécie de "Idade de ouro do Brasil holandês". Ver em Mello (2010, p. 161-327). 
em 1654, e com eles a fé reformada, restabelecendo-se assim a intolerância religiosa da Igreja Católica Romana, pois, de acordo com Schalkwijk (1997, p. 2), "não havia lugar para qualquer igreja evangélica debaixo da hegemonia ibérica". No decurso do século XVIII, segue-se um longo período de silêncio de registros da presença de protestantes na Colônia, motivado por uma forte repressão a estrangeiros oriundos de países dominados por outra fé 9 .

Com a transferência da sede do governo português para a cidade do Rio de Janeiro o protestantismo no Brasil adquiriu espaço e relevância histórica e social. Com a presença, principalmente, de grupos ingleses e alemães o protestantismo ganhou espaço para ser tolerado no seio de uma sociedade cujas premissas, tanto religiosas quanto políticas, eram dadas pela presença da Igreja Católica. O espaço aberto para a entrada de protestantes e a abertura à tolerância de culto na colônia brasileira deu-se por meio da oportunidade estabelecida na relação política entre Portugal e Inglaterra. Desde quando se estabeleceu a aliança luso-britânica em 1373, Portugal sistematicamente lançou mão da ajuda inglesa nos momentos de grande aperto. Entretanto, a história atesta uma grande vantagem comercial para a Inglaterra, que, na condição de parceiro mais forte, procurava tirar vantagens dessa relação. Embora Portugal, sob o governo do Marquês de Pombal (1750-1777), tenha reagido contra tal domínio, as contingências históricas foram menos favoráveis a Portugal (REILY, 1984, p. 24).

Em 26 de setembro de 1793, acuado pelas forças napoleônicas, a realeza portuguesa se viu obrigada a firmar um acordo de cooperação mútua com a Inglaterra, contra as pretensões expansionistas da França. Em meio ao bloqueio continental estabelecido pelos franceses, em 1807, o regente D. João decidiu, depois de longa hesitação, entre a adesão ao sistema napoleônico e a fidelidade à Inglaterra, emigrar para sua colônia americana (PRADO JR, 1990, p. 126) sob a proteção da Inglaterra. Tal relação prenunciava o futuro eminente para o Brasil, que ficou selado aos 28 de janeiro de 1808 com a abertura dos portos aos navios não-portugueses por motivos de obrigação e agradecimento. Por isso até o fim da Guerra Continental os ventos costeiros inflaram com generosidade as velas das embarcações inglesas, francesas, norte-americanas, alemãs e de outras nações inaugurando uma nova época, inclusive, como nos diz Hoornaert, "para o catolicismo no Brasil" que "deixou de ser unicamente lusitano e recebeu os impactos da romanização, e também deixou de ser a única, pois o protestantismo entrou com os primeiros viajantes estrangeiros" (1992, p. 310).

Desse relacionamento, certamente o Brasil gozou de benefícios se levarmos em conta a infraestrutura implantada para permanência da corte portuguesa no Rio de Janeiro e a abertura dos portos, que apesar de tudo, estimulou as atividades econômicas no país. No plano político é possível dizer que este acontecimento firmou o alicerce onde seriam erguidos os pilares de sustentação para a independência do Brasil; no sociocultural, ocorreu a importação de novas ideias, vindas de além-mar, principalmente trazidas pelos ventos da fé protestante a um país que estava marcado indelevelmente pela presença da Igreja Católica.

9 Esta época foi chamada de "idade das trevas" por Erasmo Braga e Kenneth Grubb. Ver em The republic of Brasil - a survey of the religious situation. London/New York/Toronto: World Dominion Prees, 1932. 
Embora possa se atribuir aos ingleses a tolerância do culto protestante em terras brasileiras, "sob o ponto de vista institucional, isto é, com a formação de comunidades permanentes, são os imigrantes alemães os pioneiros na implantação do protestantismo no Brasil" (MENDONÇA; VELASQUES FILHO, 1990, p. 27), apesar de seguirem praticamente os mesmos passos dos anglicanos e organizarem igrejas voltadas para o atendimento restrito aos seus próprios imigrantes. Nesse período surgiram também protestantes da Suíça, da Irlanda e de outros povos que a Reforma tinha alcançado. Em nenhum desses grupos encontra-se aspiração propriamente de cunho missionário.

O tratado de Comércio e Navegação firmado entre Portugal e Inglaterra em 19 de fevereiro de 1810, continha no Artigo 12 as linhas mestras da liberdade religiosa ${ }^{10}$ que mais tarde seriam inseridas na primeira Constituição Imperial de $1824^{11}$. Com isso o governo garantia a tolerância de culto aos protestantes, desde que esses não usassem deste benefício para fazerem prosélitos; não perturbassem a ordem pública; não difamassem a religião estabelecida do Império; e não discursassem, em reuniões públicas, doutrinas que diretamente destruíssem as verdades fundamentais da existência de Deus e da imortalidade da alma ${ }^{12}$.

Tanto o Artigo 12 do Tratado do Comércio, quanto, posteriormente, o artigo cinco da Constituição do Império estão carregados muito mais de interesses comerciais do que propriamente de benevolência e respeito à iniciativa religiosa protestante. A Igreja Católica, mesmo mantendo o status de Igreja oficial e contrária à presença protestante, não podia fazer nada mais, além de duramente atacá-la através da utilização dos meios de comunicação disponíveis ao seu alcance. Posteriormente essas limitações seriam superadas na Constituição Republicana de 1891, de forte influência liberal e positivista, e que consagraria a completa liberdade religiosa ${ }^{13}$. A obra de David Gueiros Vieira O protestantismo a maçonaria e a questão religiosa no Brasil (1980) traz uma importante contribuição para a compreensão da entrada e permanência dos primeiros protestantes no Brasil colonial e os conflitos daí decorrentes.

Foi somente a partir da segunda metade do século XIX que os protestantes de origem missionária desembarcaram nos portos brasileiros. Originários, principalmente, de juntas missionárias norte-americanas e europeias, Metodistas, Presbiterianos, Batistas e Congregacionais chegaram ao Brasil com propósitos idênticos de evangelizar e educar a nação. Todos estes grupos tinham em comum uma mesma imagem de si mesmos e se achavam arautos do progresso e portadores de uma nova visão de mundo e tinham a educação como estratégia missionária. Ao lado de uma igreja, erguia-se também uma escola. E quando isto

10 Art. 12. Os súditos britânicos e todos os outros estrangeiros residentes nos domínios de Portugal, terão perfeita liberdade religiosa, lhes sendo permitido construir Igrejas e Capelas, com certas restrições quanto ao aspecto exterior (...).

11 Art. $5^{\circ}$. A religião Católica Apostólica Romana continuará a ser a religião do Império. Todas as outras religiões serão permitidas com seu culto doméstico, ou particular em casas para isso destinadas, sem forma alguma exterior de templo.

12 Conforme as Leis 276, 277 e 278 do Código Criminal do Império do Brasil, sancionado pela lei de 16 de dezembro de 1830, aplicáveis ao Artigo Cinco da Constituição de 1824.

13 Art. 72. Parágrafo $3^{\circ}$ Todos os indivíduos e confissões religiosas podem exercer pública e livremente o seu culto, associando-se para esse fim e adquirindo bens, observados as disposições do direito comum. 
não era possível, "o templo era utilizado para o culto e para o ensino". Ademais, pondera Bastian, "o projeto escolar permitia difundir, fora do recinto do templo e da comunidade protestante, valores religiosos e políticos democráticos, assim como propor uma base moral e religiosa para a futura democracia liberal" (BASTIAN, 1994, p. 129).

O protestantismo oferecia para aqueles desejosos de uma reforma nos modos sociopolíticos e econômicos da época um rompimento com os antigos valores representados pela Igreja Católica e sua sociedade provincial, sacralizada, hierarquizada, elitista e aristocrática. Contudo, de acordo com David Gueiros Vieira, pela multiplicidade de suas seitas, entre os anos de 1808 a 1875, a sociedade brasileira via os grupos protestantes sob quatro ângulos diferentes e equidistantes, a saber: "a) como "modernistas" indiferentes e irreligiosos; b) como moderadamente religiosos, mas pregadores do "progresso", da indústria e do comércio; c) como zelosos pregadores do Evangelho e distribuidores de Bíblias; e por fim; d) como místicos e fanáticos messiânicos" (Cf. GUEIROS VIEIRA, 1980, p. 49).

Muito mais do que uma simples forma de se expressar uma fé num Deus, o protestantismo era visto, antes de tudo, como portador de uma nova visão de mundo, um passaporte para o mundo moderno, que já havia se manifestado na Europa e que agora surgia no horizonte americano como uma bandeira viva do progresso, principalmente por aqueles que acalentavam mudanças de rumos para o Brasil. Estas representações atribuídas ao protestantismo missionário determinou o modo pelo qual os missionários conduziram suas estratégias de penetração na sociedade brasileira fortemente estruturada pela presença da Igreja Católica (Cf. VIEIRA, 2006, p. 145).

\section{O PROTESTANTISMO MISSIONÁRIO}

Grosso modo, é possível dizer que a linha diretriz do pensamento protestante que chegou ao Brasil tem suas origens no puritanismo inglês que por questões político-religiosas emigrou para as colônias Americanas, em 1620, mas que encontra seus fundamentos constitutivos no ajustamento que sofreu com as novas expressões religiosas que para lá também imigraram, principalmente com o metodismo wesleyano. Classificado como um "protestantismo de povoamento", de acordo com Mendonça, o protestantismo norte-americano se formou "à medida que protestantes europeus passavam para as possessões inglesas à busca de novas condições de vida" (MENDONÇA, 1984, p. 43). Contudo, esta constatação deve ser submetida às diversas situações históricas, uma vez que não podemos afirmar que os mesmos traços encontrados naquele tipo de protestantismo também possam ser encontrados de igual forma no protestantismo que mais de dois séculos depois chegaria ao Brasil. Assim cabe uma sucinta abordagem histórica a respeito do itinerário do protestantismo missionário antes de chegar ao Brasil, a fim de elucidar sua configuração histórica atual no cenário brasileiro.

Após a travessia do Atlântico, à semelhança do Mar Vermelho pelos israelitas em busca da "terra prometida", os colonos que vieram para o Novo Mundo firmaram em 11 de novembro de 1620, por meio de um acordo voluntário entre homens de direitos iguais, um instrumento de autogoverno, que ficou conhecido como o Pacto do Mayflower. Para 
aqueles colonos a viagem tinha sido empreendida "para a glória de Deus e para o avanço da fé cristã" e para a honra do rei e país. É nesse pacto basilar que os peregrinos "na presença de Deus e cada um na presença dos demais", compactuaram e combinaram-se como "um corpo político e civil"14. Com isso encontraram uma forma racionalizada de conduzir suas convicções político-religiosas e passaram a se sentir "com o direito e a liberdade de construir um Estado Puritano (Puritan State) para servir de orientação a todos os verdadeiros cristãos em todos os lugares. Sentiam-se como o Povo Escolhido (God's Chosen People), tanto no sentido espiritual como intelectual" (Cf. MENDONÇA, 1984, p. 45). Sob a forma organizativa e teológica do calvinismo, racionalismo e do elitismo como motivações principais às suas ações, se viam fortalecidos no confronto com outros grupos religiosos que para lá também imigraram ${ }^{15}$. Entretanto, é nesse confronto com as novas ideias e práticas religiosas e políticas adversas que se encontram os elementos condicionantes do futuro do protestantismo que irá desenvolver-se na América do Norte.

Muito resumidamente, com o passar dos anos, o saldo desse confronto foi o declínio do fervor religioso e consequentemente da perda de influência do puritanismo sobre o modo de organização político, religioso e social das colônias inglesas. Três fatores contribuíram para o enfraquecimento do puritanismo e para a configuração do protestantismo norte americano. O primeiro pode ser encontrado na difusão das ideias do Iluminismo na América no final do século XVII e sua centralidade nos princípios racionais do pensamento humano ${ }^{16}$; o segundo está presente no desenvolvimento do fenômeno religioso conhecido como denominacionalismo, observado na base da formação do protestantismo americano em que prevalecia mais uma ética de casta em detrimento de uma ética da fraternidade, fruto do confronto com as diversas formas de organização religiosa (teologias, doutrinas, disciplinas eclesiásticas) e da dinâmica do processo de diferenciação étnico-cultural existente entre elas ${ }^{17}$; o terceiro fator explicativo para o enfraquecimento do puritanismo se deu no grande movimento do despertar religioso ocorrido na primeira metade do século XVIII, representado principalmente pelas igrejas "fronteiriças à civilização" e na incapacidade de ajuste do puritanismo a esta nova forma de organização da vida religiosa. O resultado desse conflito foi a separação entre a fé da fronteira e a religião das comunidades estabelecidas profundamente afetadas por sucessivos cismas no interior de suas igrejas (NIEBURHR, 1992, p. 96), e o contorno de um tipo de protestantismo que iria se afirmar naquelas condições.

\footnotetext{
14 O documento original se perdeu. Restaram apenas as anotações do diário de Willian Bradford, aceitas pela comunidade de historiadores. Este documento está mantido na Biblioteca Pública de Massachussets. Utilizo-me aqui da cópia encontrada no site da Universidade Carlos III de Madrid, http://ocw.uc3m.es/historia-del-derecho/historia-del-constitucionalismo-americano/otros-recursos-2/tema-1-origenes-coloniales-del-constitucionalismo-norteamericano/pacto-del-mayflower-1620/at_download/file acessado em 24/07/2018.

15 Intensas e sucessivas ondas de imigrações europeias tomaram conta do território Americano no final do século XVI e por todo século XVII, eram em sua maioria luteranos suecos e alemães, presbiterianos escoceses, anglicanos ingleses, quakers, huguenotes, reformados holandeses, católicos romanos, judeus mas também escravos negros e aventureiros.

16 Ver Mendonça (1984, p. 49).

17 Ver Nieburhr (1991).
} 
Grosso modo, o protestantismo transplantado para o Brasil, definido como protestantismo histórico de missão, foi fortemente influenciado pela visão de mundo da igreja metodista norte-americana que encontrou no confronto de adaptação nos Estados Unidos as condições ideais para o seu desenvolvimento. "As outras denominações", adverte Mendonça, "como os presbiterianos por exemplo, mais formalistas, ajustavam-se com certa dificuldade a essas novas condições e por isso ficaram mais ou menos na esteira dos metodistas, que cresceram extraordinariamente" (1984, p. 50).

$\mathrm{O}$ primeiro protestante norte-americano a empreender uma viagem missionária ao Brasil foi o jovem metodista episcopal Fountain E. Pitts (1808-1874) que permaneceu no Rio de Janeiro de 1835 a 1836 quanto retornou aos Estados Unidos. Por recomendação de Pitts, no mesmo ano chegou ao Brasil o rev. Justin Spaulding (1829-1905) considerado, pela historiografia protestante, como o primeiro missionário metodista a se estabelecer no Brasil. Entretanto a missão Spaulding permaneceu por apenas seis anos (1836-1841) por motivo de grave crise financeira gerada pela grande depressão econômica nos Estados Unidos de $1837^{18}$. Entre os anos de 1837 e 1840, também esteve no Brasil o missionário metodista Daniel P. Kidder (1815-1891), além de dar assistência à sociedade americana dos amigos dos marítimos como capelão, como os anteriores, foi o responsável por sistematizar na obra Reminiscência de viagens e permanência no Brasil: Rio de janeiro e Província de São Paulo (1845) suas principais impressões históricas e geográficas sobre o Brasil. Kidder publicou ainda em parceria com o também capelão presbiteriano James C. Fletcher (1823-1901), O Brasil e os brasileiros: esboço histórico e descritivo (1876) ${ }^{19}$. O trabalho missionário metodista só se estabeleceria permanentemente no Brasil com a imigração dos confederados norte-americanos para Santa Bárbara do Oeste, com a presença do rev. Junius Eastham Newman (1819-1895), em 1867 (VIEIRA, 2016, p. 140).

Contudo a obra congregacional é considerada a primeira "igreja de missão" a se instalar permanentemente em solo brasileiro (REILY, 1984, p. 95). No dia 10 de maio de 1855, desembarcou no Rio de Janeiro, após um mês de viagem, o médico missionário escocês Robert Reid Kalley (1809-1888) e sua esposa Sarah Kalley (1825-1907). O casal fixou moradia em Petrópolis, pois encontraram no clima e no aspecto da cidade um lugar mais adequado para residir. De acordo com Buriti e Barros, "uma das estratégias de evangelização de que o casal Kalley lançara mão é o da escolarização, procurando relacionar o contexto de aprendizagem da Bíblia e de livros cristãos com as práticas de ler e escrever" (2016, p. 22). Fundaram na cidade de Petrópolis a primeira escola dominical do país. O Casal Kelley deu grande contribuição para a difusão e permanência do protestantismo no Brasil.

\section{Algumas CONSIDERaÇões PROVISÓRIaS}

Falar sobre a presença do protestantismo no Brasil é, antes, contextualizar e sistematizar de maneira crítica a trajetória histórica em sua forma multidimensional de modo

18 Sobre os motivos do abandono da missão brasileira ver: (REILY, 1984, p. 84-85)

19 Ver em (GUEIROS VIEIRA, 1980, p. 61-94).

198 Comunicações | Piracicaba | v. 25 | n. 2 | p. 189-206| maio-ago. 2018 
a conferir um sentido histórico e social a este movimento religioso que surgiu na Reforma Quinhentista inserida no "quadro das revoluções liberais e democráticas, do capitalismo, da Revolução Industrial, da descolonização e constituição do Novo Mundo Americano" (Cf. MAGALHÃES, 2016, p. 12) e perceber como suas representações foram construídas e apropriadas pelos diferentes grupos e ele relacionados. Tentamos neste texto percorrer, ainda que de maneira bastante concisa este itinerário até a chegada dos primeiros missionários protestantes no Brasil. Procuramos, assim, entender como a formação histórica do protestantismo norte-americano foi responsável por um tipo de protestantismo que seria "transplantado" em definitivo para cá na segunda metade do século XIX.

A marcante influência que a cultura norte americana exerceu sobre a sociedade brasileira nesse período pode ser encontrada no pensamento de alguns dos mais destacados intelectuais brasileiros. Como já se escreveu antes (BARBANTI, 1977; VIEIRA, 2006), a educação trazida por estas sociedades pode ser entendida tanto como uma estratégia de acesso ao poder por parte dos republicanos que as utilizaram e propagandearam, como da constituição de uma "pretensa" hegemonia cultural e religiosa almejada por parte dos primeiros missionários no Brasil.

Como nos lembra Chartier "as lutas de representações têm tanta importância como as lutas econômicas para compreender os mecanismos pelos quais um grupo impõe ou tenta impor, a sua concepção de mundo social, os valores que são seus, e o seu domínio (1990, p. 17). Tanto um quanto o outro necessitavam dessa união, sem a qual poriam em risco as suas reais pretensões. A eficácia simbólica desta representação se sobrepunha aos papéis reais, dados os interesses que teriam de ser preservados. Os imigrantes e os missionários que aqui chegaram, eram antes de tudo norte-americanos, portadores de um mesmo ideal que os tornavam distintos dos demais, segundo um modelo próprio e pertencente a uma unidade de relações sociais, por muitos, considerada superior.

A pesquisa sobre as influências do pensamento reformado no campo da educação brasileira ainda tem muito para nos oferecer, permitindo-nos uma compreensão tanto das características do tipo de protestantismo que aqui estabeleceu suas escolas quanto as condições sócio-político-econômicas que viabilizaram a implementação e expansão dessas instituições. Queremos, aqui, deixar nossa contribuição por meio deste Dossiê "Pensando a Educação 500 anos após Wittenberg", por nós organizado, que contém seis artigos selecionados dentre os recebidos após chamada aberta realizada no primeiro semestre de 2017 . Neste dossiê, apresentamos tanto artigos que se voltam ao contexto dos primórdios da Reforma Protestante, seja olhando para Lutero, seja para Melanchton, quanto artigos que se voltam para as relações entre os movimentos protestantes e a implementação de escolas no Brasil.

Iniciamos com o texto de Norberto Dallabrida, intitulado "As reformas religiosas e o nascimento da escolarização ocidental". Neste, o autor analisa o nascimento da escola moderna no Ocidente na sua íntima relação com as disputas religiosas modernas que levaram católicos e protestantes a constituírem essas instituições de instrução e de formação. Nas palavras do autor: 
as reformas religiosas desencadeadas pela publicação das 95 teses de Lutero, em 1517, construíram o nascimento da escolarização ocidental a partir de diferentes matrizes cristãs - protestantes e católica. Trata-se de um divortium aquarum que fez emergir a escolarização no espaço ocidental, marcada pela disciplina moderna e materializada por dispositivos como o controle do tempo, o esquadrinhamento do espaço, a organização das forças, o clima de concorrência e de premiação discente e a ênfase nos castigos morais. (DALLABRIDA, 2018)

Para tal, recorre ao expediente de analisar três textos contemporâneos que tratam da escolarização ocidental numa temporalidade de longa duração. São eles: "Produção da escola/ produção da sociedade: análise sócio-histórica de alguns momentos decisivos da evolução escolar no ocidente", do sociólogo André Petitat (1994); "Arqueología de la escuela", dos sociólogos Julia Varela e Fernando Alvarez-Uría (1991); e "A invenção da sala de aula: uma genealogia das formas de ensinar”, dos historiadores Inés Dussel e Marcelo Caruso (2003).

A análise destes textos permitiu ao autor o destaque de elementos fundamentais para a compreensão da escola moderna, a saber: a descontinuidade das práticas escolares que ocorriam no colégio e na Universidade medieval; a disciplina moderna (Foucault) e seus dispositivos no âmbito escolar em relação às práticas de "governo" que se desenvolviam naquele tempo; o fanatismo como consequência da escolarização utilizada como guerra religiosa; e, por fim, as diferenças de classes presentes na diferenciação da escolarização realizada nos colégios e nas escolas elementares.

Do macro para o micro, podemos compreender de que maneira a escola moderna se materializa na obra de um dos reformadores. É o que podemos ver no artigo de Rodrigo Pinto de Andrade, Francielle Aparecida Garuti de Andrade, Cézar de Alencar Arnaut de Toledo, intitulado. "Reforma Protestante e educação escolar: as contribuições de Felipe Melanchthon (1497-1560)". Já nas primeiras palavras, os autores apontam para a relevância e a necessidade de se olhar para Melanchton:

Suas propostas educacionais são pouco conhecidas entre nós, pois grande parte de sua obra ainda não foi traduzida para a língua portuguesa, por isso, sua atuação na construção de escolas e seu pensamento pedagógico foram pouco explorados. Todavia, sua obra contribuiu para o processo de consolidação e expansão dos pressupostos religiosos e educacionais da Reforma na Alemanha. (ANDRADE; ANDRADE; ARNAUT DE TOLEDO, 2018)

Melanchton compreendia a educação como "um instrumento fundamental para a consolidação e difusão das doutrinas da fé protestante" (ANDRADE et al., 2018) e estabeleceu nas escolas uma relação entre luteranismo e humanismo, aliando um currículo humanista à formação cristã protestante. Esse currículo se voltava à formação do homem fiel, que, escolarizado, permitiria uma "consolidação da religião" e "renovação da sociedade".

Do nome menos conhecido da Reforma ao nome mais conhecido. Lutero é um autor amplamente estudado e em diferentes áreas do conhecimento. No entanto, direcionar nosso olhar para novas leituras de sua obra pode ser um exercício profícuo, como o que reali- 
zaram Evaldo Luis Pauly e Anselmo Ernesto Graff, no artigo "A influência de Lutero na pesquisa brasileira em educação: uma nova perspectiva teórica"

Os autores se propõem a ir, na obra de Lutero, além dos textos mais tradicionalmente citados na área de educação: textos que tratam das concepções políticas do reformador alemão, mas que são, como eles apontam, periféricos em sua obra. Conforme afirmam os autores:

Uma mudança no enfoque pedagógico tradicional sobre Lutero talvez seja
interessante porque os textos políticos de Lutero nos parecem menos insti-
gadores para a pedagogia do que as concepções luteranas de eclesiologia,
antropologia e catequética, temas centrais na teologia da Reforma. A hipótese
do artigo é que Lutero, como pensador político, está imerso na cultura e no
paradigma social da cristandade, portanto, não poderia conceber um Esta-
do democrático e laico porque não rompeu completamente com a concepção
político-religiosa da cristandade europeia. Essa hipótese considera que, em
termos políticos modernos, Lutero foi democrático na gestão paroquial (po-
der municipal), aristocrático no principado (poder provincial) e teocrático no
Reino (poder nacional). (PAULY, GRAFF, 2018)

Ao olharem para a teologia luterana e para o debate sobre a educação universal especialmente no confronto das concepções de ser humano de Erasmo e Lutero (de certo modo retomado no confronto das concepções pedagógicas de Rousseau e Kant), os autores abrem espaço para uma compreensão do Estado Democrático de Direito no século XXI. Destacamos estas palavras de sua conclusão:

A teologia pode ajudar a pedagogia na compreensão racional da transcendência necessária ao ato de educar no sentido de que tal ato supera a contradição entre o inédito e o viável. A crença do professor no aluno é racional e, ao mesmo tempo, emocional, portanto, não gera culpa, mas responsabilização objetiva. (PAULY, GRAFF, 2018)

É no Estado Democrático de Direito do século XXI que também se encontram as questões levantadas por Luciane Muniz Ribeiro Barbosa e Ana Elisa Spaolonzi Queiroz Assis, em seu artigo "Direito à educação e 500 anos de Reforma Protestante: as contribuições de Martinho Lutero”. Neste, as autoras abrem espaço para pensarmos na relação entre as concepções de Lutero sobre direito à educação e o que delas permanece ainda hoje nas concepções contemporâneas a respeito. Ao observar a história do direito à educação no Brasil, as autoras mapeiam a variação da compreensão de quem são os "todos" que têm direito à educação escolar e como essa definição está carregada de debates e conflitos.

Parte desses conflitos já estavam presentes nas questões que Lutero defendeu, especialmente em sua compreensão de educação escolar, quando amplia o público alvo da educação e a propõe como pública estatal. Como afirmam as autoras:

Dessa maneira, ressalta-se que o princípio da obrigatoriedade presente nas propostas educacionais de Lutero atribui aos pais o dever de enviar os filhos à escola; às crianças, a obrigatoriedade de frequência; e às autoridades, a garantia 
de oferta e supervisão quanto ao atendimento. Uma situação bastante clara nos dias atuais, em especial considerando o ordenamento jurídico brasileiro e que, inclusive, tem repercussões na forma de reclamar o direito frente ao Poder Judiciário. (BARBOSA; ASSIS, 2018).

As reflexões das autoras levantam o necessário caráter político do debate ao direito à educação quando questionam a efetivação plena do direito à educação no século XX, especialmente no Brasil, apontando que

\begin{abstract}
países como o Brasil têm alterado o seu ordenamento jurídico ao longo dos anos, incorporando e ampliando princípios reconhecidos internacionalmente como pertencentes ao direito à educação, contudo, os índices sociais e a extrema desigualdade de renda têm revelado que ao longo destes cinco séculos o "para todos" tornou-se promessa e, a igualdade, uma ilusão. (BARBOSA; ASSIS, 2018).
\end{abstract}

Se de um lado podemos relacionar as propostas de Lutero sobre educação com o debate educacional contemporâneo em um âmbito geral, por outro, podemos observar como as ideias desse autor chegaram e se difundiram no Brasil em um contexto histórico específico. Isto compreendemos a partir da leitura do artigo de Ademir Valdir dos Santos e Elcio Cecchetti, intitulado "A presença de Lutero no Brasil: o poder da fé, a imigração alemã e a educação".

Neste texto, os autores se voltam para a imigração alemã no Brasil entre a segunda metade do século XIX e primeiras décadas do XX no sul brasileiro, como um espaço privilegiado de observação. Eles buscam compreender "o modo como o pensamento luterano reverberou nas regiões meridionais, impulsionando a fundação de escolas para a formação da infầncia no contexto da imigração alemã." (SANTOS; CECCHETTI, 2018).

Ao apontar para o investimento em educação no sul do Brasil nas regiões onde haviam colônias de imigrantes alemães, em especial luteranos, os autores mostram o modo como os mais velhos "defendiam a necessidade de escolas para que seus filhos tivessem acesso aos fundamentos da fé, além de serem formados para enfrentar as dificuldades da vida num país estranho e de hábitos culturais diferentes". (SANTOS; CECCHETTI, 2018). O exercício histórico que propõem no artigo permite entendermos o que eles denominaram de "amálgama histórico catalisado pela fé" que reunia "as relações entre o pensamento de Lutero sobre a educação, a imigração alemã que trouxe para o sul do Brasil o luteranismo, e o processo de criação e manutenção de escolas nas comunidades de religião luterana" (SANTOS, CECCHETTI, 2018).

No entanto, a vinda das ideias protestantes para o Brasil e seu impacto na criação e expansão de escolas não se deu sem conflitos com a Igreja Católica. Nosso dossiê conclui com uma das expressões desse conflito, analisada por Ramsés Nunes e Silva no artigo, "Pela fé, contra o herege: Odilon Alves Pedrosa e os debates antiescola protestante na Gazeta de Nazaré (1931-1935)" 
Em Nazaré da Mata, Pernambuco, o padre católico Odilon Alves Pedrosa não mediu esforços contra a presença de escolas protestantes, atacando-as, entre outros meios, por artigos publicados na imprensa:

\begin{abstract}
Naquele momento suas atribuições, entre elas a função de pároco, acabaram por ser minimizadas. Outras ações naquele palco convulsionado que era Pernambuco se mostraram imprescindíveis: 1) as de teólogo e doutor em Direito Canônico, basilar para a diocese que o abraçava; 2) jornalista diletante e militante político, com já larga experiência na editoração de periódicos; e 3) educador católico engajado, atividade que funcionaria como lastro de sua produção e afirmação teórica, num primeiro momento, ali mesmo em Nazaré da Mata, junto a novos seminaristas e também alunos (as) internos (as), nos colégios confessionais locais. (SILVA, 2018)
\end{abstract}

Olhar para Odilon Pedrosa em Nazaré da Mata é permitir uma compreensão de como um contexto local espelhava uma situação nacional na qual a Igreja se posicionava diante de diversos inimigos. É o que podemos ver no artigo:

É de se observar, entre as missões eclesiásticas, particularmente dadas a um recém-ordenado padre, o combate a outras profissões religiosas e ideários políticos e filosóficos, entre eles, o protestantismo, espiritismo, laicismo e a maçonaria, princípios e confissões que se apresentavam em franca expansão na cidade de Nazaré da Mata, nos últimos anos, parte deles potencializados numa esfera cosmopolita, que recebia uma gama cada vez maior de partícipes civis secularizados. (xxxx, 2018)

O padre Odilon Pedrosa assume um movimento de ataque, via imprensa, ao crescimento do protestantismo e de suas escolas, em termos como "Eis os imorais a tentarem as escolas com as mentiras teutônicas. Qual família deve confiar seus filhos a um pastor? Tem ele qualquer formação moral, espiritual ou pedagógica para tanto? Temos nossas dúvidas" (PEDROSA apud SILVA, 2018). Podemos, então, com este artigo ampliar nossa compreensão sobre os espaços de disputa nos quais se desenvolveu a educação escolar nas primeiras décadas da república.

A chamada de um dossiê temático é a abertura para um espaço de possíveis convergências e divergências, mas, principalmente, um espaço para observar tanto o que se pesquisa hoje quanto as potencialidades de novas pesquisas dentro do tema escolhido. O que aqui esperamos foi ter contribuído não apenas para dar visibilidade às pesquisas já realizadas sobre a relação entre educação e a Reforma no contexto de uma efeméride, mas também apontar para diferentes modos de abordar essa relação na pesquisa realizada no Brasil.

\title{
REFERÊNCIAS
}

ANCHIETA, J. Cartas: Informações, fragmentos históricos e sermões. Belo Horizonte: Itatiaia/ São Paulo: Edusp, 1988, p. 167. 
ANDRADE, Rodrigo Pinto; ANDRADE, Francielle Aparecida Garuti de; ARNAUT DE TOLEDO, Cézar de Alencar. Reforma Protestante e educação escolar: as contribuições de Felipe Melanchthon (1497-1560). Comunicações (UNIMEP), v. 25, n. 2, mai-ago/2018.

BARBANTI, Maria L. S. H. Escolas americanas de confissão protestante na província de São Paulo: um estudo de suas origens. 228 f. Dissertação (Mestrado em Educação) FEUSP, São Paulo, 1977.

BARBOSA, Luciane Muniz Ribeiro; ASSIS, Ana Elisa Spaolonzi Queiroz. Direito à educação e 500 anos de Reforma Protestante: as contribuições de Martinho Lutero. Comunicações (UNIMEP), v. 25, n. 2, mai-ago/2018.

BURITI, Iranilson; BARROS, Moisés A. "Onde Deus nos outorga constante instrução": a educação como tática de inserção do Protestantismo no Brasil. In: VIEIRA, Cesar Romero A.; NASCIMENTO, Esther Fraga Vilas-Bôas C. (Orgs.). Contribuições do protestantismo para a história da educação no Brasil e em Portugal. Piracicaba: Editora Unimep, 2016, p. $21-46$.

BASTIAN, Jean-Pierre. Protestantismos y modernidade latinoamericana: história de unas minorias religiosas activas en América Latina. México: Fondo de Cultura Econômica, 1994.

. O protestantismo na América Latina. In: DUSSEL, Enrique (Org.). 500 anos de história na América Latina. São Paulo: Edições Paulinas, 1992, p. 467-510.

CHARTIER, Roger. A história cultural: entre práticas e representações. Lisboa: Difel, 1990.

DALLABRIDA, Norberto. As reformas religiosas e o nascimento da escolarização ocidental. Comunicações (UNIMEP), v. 25, n. 2, mai-ago/2018.

GUEIROS VIEIRA, David. O protestantismo, a maçonaria e a questão religiosa no Brasil. Brasília: Editora Universidade de Brasília, 1980.

HILSDORF, Maria Lúcia Spedo. Educadoras metodistas no século XIX: uma abordagem do ponto de vista da História da Educação. In: Revista do Cogeime, São Paulo, ano II, jun. 2002, pp. 93-98.

HOORNARERT, Eduardo. A Igreja no Brasil. In: DUSSEL, Enrique (Org.). 500 anos de história na América Latina. São Paulo: Edições Paulinas, 1992, p. 297-317.

LEONARD, Émile-G. O protestantismo brasileiro. São Paulo: ASTE, 1963.

LÉRY, de Jean. Viagem à terra do Brasil. Trad. Sérgio Milliet, Rio de Janeiro: Biblioteca do Exército Editora, 1961.

MELLO, Evaldo Cabral de. (Org.). O Brasil holandês. São Paulo: Penguin Classics, 2010.

MENDONÇA, Antônio G. O Celeste Porvir: A inserção do protestantismo no Brasil. São Paulo: Ed. Paulinas, 1984. 
. Protestantismo de origem missionária. In: MENDONÇA, Antônio G.; VELASQUES FILHO, Prócoro. Introdução ao protestantismo no Brasil. São Paulo: Edições Loyola; Programa Ecumênico de Pós-Graduação em Ciências da Religião, 1990, p. 11-59. MAGALHÃES, J. Prefácio. In: VIEIRA, Cesar Romero A.; NASCIMENTO, Esther Fraga Vilas-Bôas C. (Orgs.). Contribuições do protestantismo para a história da educação no Brasil e em Portugal. Piracicaba: Editora Unimep, 2016, p. 7 - 13.

NIEBUHR, H. Richard. As origens sociais das denominações cristãs. São Paulo: ASTE: Programa de Pós-Graduação em Ciências da Religião, 1992.

PAULY, Evaldo Luis; GRAFF, Anselmo Ernesto. A influência de Lutero na pesquisa brasileira em educação: uma nova perspectiva teórica. Comunicações (UNIMEP), v. 25, n. 2, mai-ago/2018.

PRADO JÚNIOR, C. História econômica do Brasil. 38. ed. São Paulo: Brasiliense, 1990. PROVENÇAL, Lucien. A França equinoctial. In: Revista do Instituto Histórico e Geográfico do Brasil: Rio de Janeiro, a. 170 (444), jul./set., 2009, p. 69 - 82.

REILY, Duncan A. História documental do protestantismo no Brasil. São Paulo: ASTE, 1984.

REIS, Álvaro. O martyr Le Balleur (1567). Rio de Janeiro: Comemoração do Quarto Centenário da Reforma (31 de outubro de 1517-1917), 1917.

SANTOS, Ademir Valdir dos; CECCHETTI, Elcio. A presença de Lutero no Brasil: o poder da fé, a imigração alemã e a educação. Comunicaçães (UNIMEP), v. 25, n. 2, mai-ago/2018.

SCHALKWIJK, Francisco Leonard. Índios Evangélicos no Brasil Holandês. Revista Fides Reformata 2/1 (1997).

. A Igreja Cristã Reformada no Brasil holandês: atas de 1636 a 1648. In: Revista do Instituto Arqueológico, Histórico e Geográfico Pernambucano, LVIII, 1993, p. 145-284.

SILVA, Ramsés Nunes e. Pela fé, contra o herege: Odilon Alves Pedrosa e os debates antiescola protestante na Gazeta de Nazaré (1931-1935). Comunicações (UNIMEP), v. 25, n. 2, mai-ago/2018.

VIEIRA, Cesar Romero A. Notícias da educação metodista no Oeste Paulista: o Colégio Piracicabano. In: VIEIRA, Cesar Romero A.; NASCIMENTO, Esther Fraga Vilas-Bôas C. (Orgs.). Contribuições do protestantismo para a história da educação no Brasil e em Portugal. Piracicaba: Editora Unimep, 2016, p. 133 - 155.

. Protestantismo e educação: a presença liberal norte americana na Reforma Caetano de Campos - 1890. 2006. 204 f. Tese (Doutorado em Educação) - Faculdade de Ciências Humanas, Universidade Metodista de Piracicaba, Piracicaba, SP. 2006. 
Protestantismo e individualização: convicção e responsabilidade na esfera religiosa. 2000. 264 f. Tese (Doutorado em Ciências da Religião) - Faculdade de Filosofia e Ciências da Religião, Universidade Metodista de São Paulo, São Bernardo do Campo, 2000.

\section{Cesar Romero Amaral Vieira}

Doutor em Ciências da Religião pela Universidade Metodista de São Paulo (UMESP); Doutor em Educação pela Universidade Metodista de Piracicaba (UNIMEP); docente do Programa de Pós-Graduação em Educação da Faculdade de Ciências Humanas da Universidade Metodista de Piracicaba, Piracicaba, SP, Brasil. E-mail: cesar.vieira@unimep.br

\section{Thiago Borges de Aguiar}

Doutor em Educação pela Universidade de São Paulo; docente do Programa de Pós-Graduação em Educação da Faculdade de Ciências Humanas da Universidade Metodista de Piracicaba, Piracicaba, SP, Brasil. E-mail: thiago.aguiar1@unimep.br. 